Nuntius Antiquus, Belo Horizonte, v. 12, n. 1, p. 131-140, 2016

\title{
At peccant aliae matronaque rara pudica est: quão romana é a Helena das Heroides de Ovídio?
}

\author{
At peccant aliae matronaque rara pudica est: to what extent \\ is Ovid's Helen Roman in Heroides?
}

Sandra Maria Gualberto Braga Bianchet

Universidade Federal de Minas Gerais

Belo Horizonte, MG - Brasil

sandra.bianchet@gmail.com

Resumo: O objetivo principal do presente artigo é analisar a troca de correspondência entre Páris e Helena nas Heroides de Ovídio (carta 16 - PárisHelena; carta 17 - Helena-Páris). Nesta análise, parte-se do princípio de que o autor processa uma atualização das figuras mitológicas de Páris e Helena, imprimindo nelas traços que as caracterizam como partícipes da sociedade romana tal como retratada na poesia ovidiana, evidenciando sua romanidade: ele enquadra-se no perfil de um amante elegíaco, que busca obter a atenção de sua puella; ela assume a postura de uma autêntica matrona da viragem do século I, pronta para atender ao apelo de seu amante.

Palavras-chave: Ovídio; elegia erótica romana; Heroides.

Abstract: The main purpose of the present paper is analyzing the exchange of letters between Paris and Helen in Ovid's Heroides (letter 16 - from Paris to Helen, letter 17 - from Helen to Paris). The starting point taken here is the idea that Ovid processes a remaking of the mythological characters of Paris and Helen, printing on them some specific traces that characterizes them as members of the Roman society as portrayed in Ovidian poetry, highlighting their Roman way of living: starring him as 
132 Nuntius Antiquus, Belo Horizonte, v. 12, n. 1, p. 131-140, 2016

an elegiac lover, who goes after his puella; her as an authentic Roman matron, ready to answer to her lover's appeal.

Keywords: Ovid; Roman erotic elegy; Heroides.

Artigo recebido em 11 de dezembro de 2015 Aprovado para publicação em 12 de janeiro de 2016

\section{Introdução}

Em geral, os estudiosos da obra de Ovídio dividem as Heroides em dois conjuntos distintos de cartas: as cartas isoladas (Heroides 1 a 15), que teriam sido publicadas por voltado ano 15 a.C., e as cartas duplas (Heroides 16 a 21), trazidas a público no $2^{\circ}$ ano de nossa era (cronologia baseada na proposta de Isbell'1). No entanto, não há consenso de que todas as 21 cartas que compõem a coleção tenham sido de fato escritas por Ovídio. Para Cannon, ${ }^{2}$ a origem de tal dúvida se encontra precisamente na referência que o próprio poeta faz às Heroides (Ovídio, Amores, 2, $18,19-26)$, em que se pode identificar remissão a nove das quinze cartas isoladas, incluindo a primeira e a última (respectivamente, cartas de Penélope e de Safo). O autor, porém, lembra que o mesmo poema remete, alguns versos adiante, à carta 13 (Laodâmia a Protesilau) e à troca de correspondência entre Páris e Helena (carta 16 e 17). Quanto às cartas duplas, o principal argumento contrário à autoria ovidiana se apoia no título da obra, que se refere a cartas de "heroínas", não de "heróis", o que excluiria as cartas de autoria masculina (cartas 16, 18 e 20). Do mesmo modo, a transmissão dos manuscritos reforça a dúvida e a discussão, em especial em relação à carta 15 , que é transmitida em separado. ${ }^{3}$

Na verdade, e isto é possível perceber com nitidez, há efetivamente dois conjuntos de cartas, cada um com características peculiares que vão além de uma questão formal, uma diferença que se evidencia pela própria escolha da autoria ficcional das cartas. Enquanto as cartas isoladas são escritas por figuras femininas do universo mitológico e/ou literário, cuja história de vida amorosa é marcada por separação, abandono ou rejeição

\footnotetext{
${ }^{1}$ Ovid (1990).

${ }^{2}$ Ovid (1971).

${ }^{3}$ Ovid (1995).
} 
(Penélope, Medeia, Ariadne, Dido, Fedra, a própria Enone - esposa de Páris, etc), as cartas duplas (Páris-Helena-Páris; Leandro-Hero-Leandro; Acôncio-Cidipa-Acôncio) caracterizam-se como cartas de pretendentes a amantes/maridos que obtêm resposta, havendo, pois, efetivamente interlocução, correspondência (KNOX, 2009). Além disso, entre esses dois conjuntos, é possível pensar em uma carta de transição, com características peculiares já desde a escolha do remetente: exatamente a carta 15, que encerra a série de cartas isoladas e precede a série de cartas duplas, escrita por Safo a Faonte, cujos últimos versos (vv. 219-220) clamam por resposta hoc saltem miserae crudelis epistula dicat ("Que uma carta, cruel que seja, diga algo a esta miserável!").

Para Kennedy (2002), é importante ler as cartas tendo em mente noções de separação espacial e temporal. Penélope, por exemplo, programaticamente autora da primeira das cartas, desconhece o paradeiro de Ulisses, desconhece as circunstâncias em torno do destinatário quando, onde, se a carta será lida por seu destinatário principal -, e talvez por isso essas cartas isoladas possam ser encaradas mais como um desabafo, de maneira que o remetente se tornaria ao mesmo tempo também beneficiário de seu ato. Liveley $(2008)^{4}$ acrescenta ainda a separação emocional, que se aplicaria, por exemplo, à carta de Fedra a Hipólito. A autora argumenta que há uma reciprocidade entre tempo e narrativa nas Heroides que convida o leitor a identificar as cartas das heroínas como "histórias virtuais". A autora, porém, analisa que os poemas da coleção oferecem um monólogo trágico ou uma queixa elegíaca, mas não se configuram como uma narrativa convencional. Para Hardie (2006), a troca de cartas nas Heroides funciona como um tipo de diálogo. Spentzou (2003), por sua vez, considera as cartas das Heroides como contos.

Na dupla de cartas em foco nesta análise, no entanto, tem-se uma situação completamente distinta: Páris e Helena se encontram debaixo do mesmo teto, e a carta masculina tem função de abordagem do objeto de amor - na verdade, um meio de convencimento, uma tentativa de persuadir, de seduzir a mulher amada, por meio de argumentos, por assim dizer, convincentes. Para alguns comentadores, esse traço evidencia a natureza retórica das cartas, imprimindo a elas marcas de falta de sinceridade, já que seriam, de certa forma, próximas de suasoriae em versos, à moda de exercícios escolares de retórica (KNOX, 2002, p. 123).

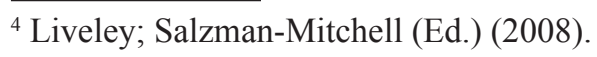


Esse comentário, apesar da evidente carga pejorativa, pode, pelo contrário, ser considerado um traço inovador das Heroides: do ponto de vista da autoria, a própria natureza das cartas insere-as no universo ficcional in principiis. Ovídio aqui traça uma linha nítida que separa o autor empírico do eu poético, em que o AVCTOR se diferencia do ACTOR talvez de uma maneira inovadora na literatura latina. Para Rimell (2006), Ovídio pode ser apontado como um escritor protonovelista, ou mesmo proto-pós-estruturalista, ao manipular categorias de escrita feminina e de discurso amoroso. Já Kennedy (2002) trabalha com a ideia de dois autores nocionais: a figura lendária e Ovídio, aos quais acrescentaríamos a ideia de dois leitores nocionais: o destinatário - em benefício ou prejuízo de quem a carta é escrita - e o público leitor de Ovídio.

Importa ainda pôr em destaque a forma de remissão à figura de Helena, quando apresentada em $3^{\mathrm{a}}$ pessoa, pelo próprio Ovídio, nas Metamorfoses. É notável que, em meio a tantas lendas, Ovídio tenha feito a opção por não dedicar espaço aos episódios dos raptos de Helena, o que denota um silêncio significativo. Reforça essa ausência o fato de que, na maior parte das vezes em que Ovídio ou algum personagem menciona Helena nas Metamorfoses, seu nome é omitido, ${ }^{5}$ sendo substituído por expressões como rapta coniux ("esposa raptada") (XII, 5), Graia marita ("grega casada") (XII, 609), Tyndaris ("filha de Tíndaro") (XV, 232), quando curiosamente Ovídio enfatiza a perda da beleza com a chegada da velhice.

Flet quoque, ut in speculo rugas adspexit aniles,

Tyndaris et secum, cur sit bis rapta, requirit.

(Ovídio, Metamorphoseon, XV, 232-233)

Chora também a filha de Tíndaro, quando ao espelho vê as rugas de velha e fica se perguntando por que teria sido raptada duas vezes.

Nas Heroides 16 e 17, por sua vez, Helena é o centro das atenções e ganha vez e voz narrativas. Para Knox (2002), Ovídio consegue aqui fazer ecoar os traços homéricos das personagens, trabalhando a

\footnotetext{
${ }^{5}$ Esse procedimento, longe de ser mero acaso, tem já precedente valioso na Eneida de Virgílio, que se recusa a referir-se à rainha Cleópatra pelo nome, chamando-a de Aegyptia coniux (En. 8, 688).
} 
familiaridade do leitor com a sequência da história. Hine ${ }^{6}$ destaca que, sob nomes e mitos gregos, o leitor das Heroides pode visualizar matronas romanas do tempo de Ovídio, mas pondera adiante que, embora se possa identificar em Laodâmia ou em Helena alguns traços de uma Otávia, ou de uma Júlia, as Heroides não seriam exatamente "romanas". Nesta análise, no entanto, parte-se do princípio de que - aceita a concepção de que a audiência de Ovídio estaria de fato bastante familiarizada com a versão canônica da história - Ovídio processa uma atualização das figuras de Páris e Helena, imprimindo nelas traços que evidenciam sua romanidade. ${ }^{7}$

\section{De Páris para Helena}

É inconteste que o ato de escrever uma carta pode transformar seu conteúdo em assunto público - carta é registro, é documento, o que seria temerário na situação que se apresenta nas Heroides 16 e 17: a de um candidato a amante, hospedado na casa de candidata a puella, quando seu marido teve de fazer uma viagem às pressas.

A autoconfiança de Páris é inegável, já que, em sua perspectiva, a situação já está definida, predeterminada - "sic placuit fatis" (Her. 16. 41). Apesar disso, na construção de sua argumentação, Páris percorre um longo caminho - é a carta mais extensa de todas (387 versos em contraposição à média geral de versos das demais cartas, que gira em torno de 160 versos), lançando mão de recursos diversos na tentativa de persuadir Helena a se tornar sua amante. Fazem parte dessa argumentação aspectos como: exposição de motivos da viagem ("nec uenio Graias ueluti spectator ad urbes [...] te peto, quam pepigit lecto Venus aurea nostro" - 33-35); narrativa do julgamento presidido por ele, bem à maneira ovidiana de introduzir narrativas nas Metamorfoses - "est locus in mediis nemo rosae uallibus Idae" - v. 53 (cf. Met. 2, 195; 8, 788; 15, 332 ); relato do percurso do navio, favorecido por Vênus; projeção da recepção que Helena terá em Troia.

$\mathrm{Na}$ carta de Páris, a imagem mais recorrente é a do fogo. $\mathrm{O}$ uso de vocábulos como flamma, ignis, uror, flammifer, ardeo, ardor se multiplica diante dos olhos do leitor/destinatário, e faz ecoar imagens de

\footnotetext{
${ }^{6}$ Ovid (1990).

${ }^{7}$ Para uma leitura política da produção poética de Ovídio, remete-se o leitor a Davis (2006).
} 
fogo da paixão (tempo 'presente', simultâneo ao momento de escritura), ao mesmo tempo em que abertamente se associam ao fogo concreto que consome Troia (projeção no tempo - 'futuro' para o destinatário, passado para o leitor).

No entanto, a partir do verso 205, Páris muda o tom da carta e se torna irônico, chegando a ser sarcástico. É quando seus versos passam a adquirir contornos elegíacos mais bem definidos, apresentando vários topoi presentes nos Amores e nas Ars amatoria: o exclusus amator, que sente ciúmes de sua amada em jantares públicos, que enumera defeitos do rival, atacando-o diretamente, que chega a ofender a amada, que, enfim, sofre por amor - é o perfil exato do amante elegíaco ovidiano. Eis alguns exemplos dessa caracterização:

Saepe dedi gemitus; et te, lasciva, notavi

in gemitu risum non tenuisse meo. (229-230)

Tantas vezes soltei gemidos, e você não segurou o riso... Eu percebi isso, lasciva, eu percebi...

a, nimium simplex Helene, ne rustica dicam, hanc faciem culpa posse carere putas? (287-288)

Ah, Helena, como você é ingênua! Isso para não dizer simplória... Acha mesmo que esse seu belo rosto pode camuflar sua culpa?

non habuit tempus, quo Cresia regna videret aptius - o mira calliditate virum!

'res, et ut Idaei mando tibi,' dixit iturus, 'curam pro nobis hospitis, uxor, agas.'

neglegis absentis, testor, mandata mariti; cura tibi non est hospitis ulla tui.(301-306)

Nunca houve momento mais apropriado para que ele fosse visitar Creta - que marido de astúcia admirável! E antes de sair ele ainda disse: 'como estou deixando ordens de que você assuma os assuntos relativos ao Ideu, sua ocupação deve ser cuidar do hóspede em meu lugar.' Eu sou testemunha de que você está negligenciando as ordens de seu marido ausente e não está tendo cuidado nenhum com o hóspede. 
Interessante notar que esse último passo, em que Páris chega a citar Menelau, possui eco na carta-resposta de Helena (epístola 17), que nos versos 159-162 também lança mão desse mesmo recurso, o de citar a fala de Menelau, em referência ao fato de transferir à esposa o cuidado não só com a casa e os assuntos domésticos, mas também com o hóspede troiano (resque domusque et tibi sit curae Troicus hospes - "Você terá de cuidar da casa, dos assuntos domésticos e do hóspede troiano").

\section{De Helena para Páris}

A carta 17 das Heroides apresenta-nos uma Helena mais maliciosa, insidiosa, uma mulher que domina o jogo de sedução de maneira primorosa. A Helena das Heroides leu a Ars Amatoriae os Amores, podemos afirmar.

Em sua carta, Helena responde às argumentações de Páris, mas intercala trechos em que demonstra estar ofendidíssima com a proposta, a trechos que declara abertamente seu desejo. Por exemplo, os versos iniciais da resposta de Helena poderiam seguramente ser lidos por Menelau, que por certo ficaria orgulhoso de sua esposa casta, pudica, virtuosa, digna de receber elogios como os do epitáfio romano B 843 casta pudica decens sapiens generosa probat(a) ("Casta, pudica, decente, discreta, magnânima, aprovada"). Observemos alguns dísticos:

Ausus es hospitii temeratis aduena sacris

Legitimam nuptae sollicitare fidem! (5-6)

Você, um estrangeiro, violados os pactos sagrados recebidos como hóspede, ousou inquietar a legítima fidelidade de uma mulher casada.

Fama tamen clara est, et adhuc sine crimine lusi

Et laudem de me nullus adulter habet. (19-20)

Minha reputação, contudo, é famosa, pois até agora eu me diverti sem cometer delito algum - não existe um adúltero que possa se vangloriar em relação a mim.

Sum rudis ad Veneris furtum nullaque fidelem -

Di mihi sunt testes! - lusimus arte uirum. (143-144) 
138 Nuntius Antiquus, Belo Horizonte, v. 12, n. 1, p. 131-140, 2016

Sou inexperiente em trapaças de Vênus: nunca - e os deuses são testemunhas disto - usei de artifícios para enganar meu fiel marido.

No entanto, Helena, em sua dubiedade, prima pela linguagem ambígua, pelo dizer sem ter dito, e usa excessivamente as formas subjuntivas - mormente os pretéritos imperfeito e perfeito:

his ego blanditiis, si peccatura fuissem,

flecterer; his poterant pectora nostra capi. (93-94)

A esse seu jeito sedutor eu me renderia, se estivesse predisposta a pecar. Desse jeito meu coração podia ser capturado.

Si te uidissem, primus de mille fuisses; Iudicio ueniam uir dabit ipse meo. (107-108)

Se eu tivesse visto você, dentre mil você teria sido o primeiro. Até meu marido irá me perdoar por esse veredicto.

Ferrea sim, si non hoc ego pectus amem. ferrea, crede mihi, non sum. (138-139)

Eu seria de ferro, se não me apaixonasse por você. De ferro, acredite em mim, eu não sou.

Sua ambiguidade se expressa de maneira inequívoca neste primoroso dístico:

Et libet et timeo, nec adhuc exacta uoluntas

Est satis; in dubio pectora nostra labant. (179-180)

Ao mesmo tempo em que me agrada a ideia, tenho medo...

Ainda não sei ao certo o que fazer... Meu coração oscila, hesita, está em dúvida... categórica:

Versos antes, porém, (153-156), Helena é maliciosamente at tu dissimula, nisi si desistere mavis. sed cur desistas? dissimulare potes. lude, sed occulte! maior, non maxima, nobis est data libertas, quod Menelaus abest. 
Quanto a você, disfarce! A menos que queira desistir... Mas por que desistir, quando pode disfarçar? Divirta-se, mas às escondidas. Com a partida de Menelau, foi-nos dada uma maior, não a maior liberdade...

Ao referir-se a Páris, ao mesmo tempo em que louva sua beleza, usa vocativos ofensivos: "infide, improbe, lasciue" (que ecoa o vocativo "lasciua" usado por Páris em sua carta). Helena ainda ridiculariza trechos da carta de Páris, como por exemplo a narrativa do julgamento (credere uix equidem caelestia corpora possum/arbitrio formam supposuisse tuo-121-122; "Na verdade, custa-me acreditar que corpos divinamente belos submeteram-se a um julgamento seu”), ou o trecho em que Páris afirma saber lutar:

apta magis Veneri quam sunt tua corpora Marti.

Bella gerant fortes, tu, Pari, semper ama!

Hectora, quem laudas, pro te pugnare iubeto;

Militia est operis altera digna tuis. (255-258)

Seu corpo está mais bem preparado para os combates de Vênus do que para os de Marte. Que os fortes façam guerras. Você, Páris, apaixone-se sempre! Heitor, a quem você elogia, lutará em seu lugar. Seus esforços merecem uma outra milícia...

Helena, coerentemente, encerra sua carta de maneira ambígua, deixando em aberto se vai ou não aceitar Páris - afirma que suas duas sociae terminarão a conversa, pois está cansada de escrever. A resposta à abordagem de Páris não é textual, mas o que acontece depois, todos os leitores de Ovídio, familiarizados que estão com a tradição, sabem de cor.

\section{Considerações finais}

Nas Heroides, pode-se afirmar, a narrativa ficcional em primeira pessoa (Ich Erzählung/ego-narrative) ganha contornos de sofisticação literária e se apresenta em dois planos que se intercruzam e se mesclam: o do autor em relação com seu leitor e o do remetente em relação com seu destinatário.

Rimell (2006, p. 158), ao analisar as epístolas 16 e 17, afirma: "Helen has the entire weight of Greco-Roman epic tradition against her" ("Helena tem todo o peso da tradição épica greco-romana contra 
140 Nuntius Antiquus, Belo Horizonte, v. 12, n. 1, p. 131-140, 2016

ela"). Em nossa opinião, Ovídio, em sua genialidade, consegue colocar todo o peso da tradição épica greco-romana a favor de Helena. Ovídio traz Helena para o mundo romano do séc. I d.C., ao efetuar um refinado processo de reelaboração de sua figura, e por que não dizer, um processo de metamorfose de Helena em uma autêntica matrona dos anos iniciais do séc. I de nossa era, ou seja, uma mulher casada que peca como as outras, já que, em tempos ovidianos, matrona rara pudica est...

\section{Referências}

DAVIS, P.J. Ovid and Augustus: a political reading of Ovid's erotic poems. London: Duckworth, 2006.

HARDIE, P. Ovid's poetic of illusion. Cambridge: Cambridge University Press, 2006.

KENNEDY, D. Epistolarity: the Heroides. In: HARDIE, Phillip (Ed.). The Cambridge companion to Ovid. Cambridge: Cambridge University Press, 2002.

KNOX, P. E. (Ed.). A Companion to Ovid. West Sussex: Wiley Blackwell, 2009.

KNOX, P. E. Ovid's Heroides: Elegiac Voices. In: BOYD, Barbara W. (Ed.). Brill's Companion to Ovid. E. J. Brill: Leiden, 2002. p. 117-39.

LIVELEY, G.; SALZMAN-MITCHELL, P. (Ed.). Latin elegy and narratology: fragments of story. Columbus: Ohio State University Press, 2008.

OVID. Heroides. Translated with introductions and notes by Harold Isbell. London: Penguin Books, 1990.

OVID. Heroides - selected epistles. Edited by Peter E. Knox. Cambridge: Cambridge University Press, 1995.

OVID. Ovid's Heroides. Translated by Harold C. Cannon. New York: Dutton, 1971.

RIMELL, V. Ovid's lover: desire, difference and the poetic imagination. Cambridge: Cambridge University Press, 2006.

SPENTZOU, E. Readers and writers in Ovid's Heroides: transgressions of genre and gender. Oxford: Oxford University Press, 2003. 